\title{
De la unidad suramericana a la fragmentación regional: contradicciones en la UNASUR a partir de las políticas de los gobiernos lulistas y las tensiones con las clases dominantes
}

\author{
From South American union to regional fragmentation: contradictions in UNASUR starting from Lula's \\ government policies and the tensions with the ruling classes
}

DOI: https://doi.org/10.22456/2178-8839.103015

Amanda Carolina Barrenengoa Universidad Nacional de La Plata, Consejo Nacional de Investigaciones Científicas y Técnicas, La Placa, Argentina abarrenengoa@fahce.unlp.edu.ar

\section{Resumen}

Este artículo propone abordar, a partir de las políticas promovidas por los gobiernos lulistas en Brasil, algunas de las contradicciones y asimetrías que surgieron en el seno de la UNASUR. Desde un diseño metodológico cualitativo que recupera el material de entrevistas a informantes clave junto con el análisis de fuentes oficiales y bibliografía, se abordan las tensiones que se sucedieron a partir de la reconstrucción de algunas de las principales políticas del Estado brasileño en relación a Suramérica y en vinculación con las clases dominantes. Reflexionamos en torno a las problemáticas vinculadas con la fragmentación regional que se produjo luego del impulso inicial que tuvieron los procesos de integración. Desde la singularidad de la UNASUR, se abren nuevos interrogantes a la luz de su parálisis actual. Estos nos permiten visualizar, por un lado, algunos de los avances en materia de integración que la UNASUR propició. Y, por otro lado, las problemáticas subyacentes que persistieron durante su funcionamiento hasta su reciente freno.

Palabras clave: Política Exterior Brasileña; Integración Regional; UNASUR.

\begin{abstract}
This article proposes to address some of the contradictions and asymmetries that took place in UNASUR starting from Lula's government policies in Brazil. From a qualitative methodological design that includes interviews with key informants, official sources, document analysis and bibliography, we approach the tensions that took place starting on the reconstruction of some of the most relevant policies of the Brazilian State towards South America and in relation to the ruling classes. We reflect on the problems related to regional fragmentation after the impulse that recent integration processes had. In UNASUR's singularity new questions are raised in its current break. These enable us to see on the one hand, the achievements in the South American regional integration policies that UNASUR impulsed. And on the other, underlying issues that persisted during its performance until its recent paralysis.
\end{abstract}

Keywords: Brazilian Foreign Policies; Regional Integration; UNASUR. 


\section{Las contradiciones en sus distintas escalas}

En los comienzos del siglo XXI, la región suramericana se vio transformada por un nuevo proceso de regionalismo que indicó importantes rupturas con el período de regionalismo abierto, propio de los años de hegemonía neoliberal (PADULA, 2010). A las propuestas de integración económica comercial características del siglo XX, se incorporaron nuevas instancias de cooperación política que abordaron temas como la defensa, el desarrollo de la infraestructura regional, la energía, la salud, la inclusión social y la democracia (COMINI; FRENKEL, 2014). El surgimiento y funcionamiento de la UNASUR (Unión de Naciones Suramericanas) nos permite indagar en estas dinámicas de cambio, en las cuales emergieron nuevas relaciones y disputas entre actores de la propia región y extra regionales. Son numerosas las investigaciones que identifican el nuevo siglo con la reconfiguración del mapa de la integración regional, señalando en el rechazo a la propuesta norteamericana de Libre Comercio para las Américas (ALCA) un punto de inflexión para el rediseño de América Latina (KATZ, 2006; KAN; PASCUAL, 2013; MORGENFELD, 2011; KAN, 2015). Como rasgo sobresaliente visualizamos el desarrollo de instancias alternativas, entre las que se destacan el renovado impulso de instrumentos estatales como respuesta a la profundización de la globalización, tanto al nivel de los Estados como en relación a los ámbitos de integración que se generaron, y la búsqueda de construir agendas de política exterior que buscasen una autonomía relativa en relación a EE.UU. (SANAHUJA, 2019). En el caso puntual de la UNASUR, la marcada presencia de líderes presidenciales abonó a una visión del período signada por cierto estatalismo como parte del universo simbólico de la integración.

Las preguntas que guían este artículo parten de considerar a la integración regional suramericana del período reciente como un tema de investigación que abre múltiples dimensiones de análisis posibles. Nos preguntamos por aquellos intereses que se entramaron durante los gobiernos lulistas, en tiempos de creación y funcionamiento de la UNASUR, desde el año 2008. A partir del rol brasileño en los impulsos integracionistas reconstruimos algunos de los conflictos emergentes en el cruce analítico entre políticas de integración y actores sociales de las clases dominantes que desbordan las esferas estatales. Desde una concepción sociológica, consideramos a estos procesos como recursos analíticos relevantes que nos permiten examinar las relaciones que se dieron entre el gobierno y múltiples sectores de las clases dominantes, en momentos de definiciones en torno a la inserción regional e internacional (BERRINGER, 2015; KAN, 2015). Analizamos a los Estados como unidades contradictorias a partir de los cuales indagamos en los procesos de integración suramericana, y nos preguntamos por la UNASUR en tanto bloque político institucional en el que cohabitaron múltiples relaciones de poder (BARRENENGOA, 2019).

Asimismo, en el estudio del Estado brasileño y su desenvolvimiento en el plano regional, emergen una multiplicidad de actores sociales. Entre los actores que fueron parte de la coalición de gobiernos del Partido de los Trabajadores (PT) es posible mencionar empresarios, banqueros, políticos, millonarios, personajes de la industria cultural, periodistas, representantes religiosos, entre otros (BOITO, 2017). Algunos de estos se erigieron en actores de peso para la dinámica política brasileña a raíz de que sus intereses permearon el gobierno en los terrenos de la política exterior, la estrategia de inserción regional y su política nacional (MORGENFELD, 2011; KAN, 2015; BERRINGER, 2015; MÍGUEZ, 2017). Con lo cual, en la configuración de una estrategia de amplio alcance, se entramaron diferentes actores sociales, sectores e intereses, que confluyeron en lo que Souza (2008) llama “comunidad de política exterior”. En este amplio universo participaron representantes del poder Ejecutivo y Legislativo, así como corporaciones privadas de escala internacional, grupos de interés, ámbitos de representación político gremial, organizaciones y partidos políticos, movimientos sociales y medios de comunicación (SOUZA, 2008; BERRINGER, 2005). Todos estos actores y sectores fueron parte -en diferentes circunstancias y con grados distintos de participación-, de la construcción de discursos y posiciones acerca de la política exterior brasileña y las decisiones que se tomaron en relación a la integración regional. En este entrecruzamiento de actores se sitúa nuestra lectura en torno a la política exterior y a los proyectos de integración regional en tanto configuraciones complejas (KAN; PASCUAL, 2015). Así, consideramos que existieron diversos modos en los cuales sus intereses fueron manifestados, en el marco de coyunturas puntuales. Es en este sentido que coincidimos con Kan (2015) y Berringer (2015) 
en torno a que las definiciones de un Estado en cuanto a su inserción regional e internacional -independientemente de ser tomadas por coaliciones de gobierno desde sus estructuras institucionales-, incluyen a distintos sectores y actores de las clases dominantes. En línea con estos enfoquemos abordamos la posición del Estado brasileño en instancias regionales como resultante de estas contradictorias dinámicas, y en tanto materialización de complejas relaciones y configuraciones (BARRENENGOA, 2019). Desde el comienzo, en los gobiernos petistas coexistieron elementos contradictorios, entre los cuales cobraron protagonismo las disputas entre distintos sectores sociales. En la relación entre la política interior y exterior estos elementos se observan con mayor claridad, dado que ambas dan indicios de la configuración que se dio entre los intereses del bloque de poder al interior de la formación social brasileña (BERRINGER, 2015). Así, existió una “yuxtaposición de políticas exteriores elaboradas por Brasil” (MÍGUEZ, 2017, p. 6).

En cuanto al escenario regional, analizamos la integración como parte de procesos sociales, históricos, políticos y culturales más generales. De esta manera, las acciones de los Estados en la UNASUR conllevaron una multiplicidad de actores sociales que habitaron en los entretelones de la integración (BARRENENGOA, 2019). Inscribimos las transformaciones regionales en su relación con actores y dinámicas extra regionales, en tiempos de transición y reconfiguración geopolítica (MERINO, 2018). Por lo cual, una mirada atenta a la interacción y las relaciones con los principales actores que conforman el escenario regional implica considerar a los distintos gobiernos, los proyectos regionales en cuestión y la participación de actores internacionales en estas, ya sea desde propuestas conjuntas o desde el propio modelo de inserción que los distintos actores en juego plantean (DECIANCIO; MÍGUEZ, 2020). El nuevo período de regionalismo inauguró un proceso de transición e hibridez (KATZ, 2006; SANAHUJA, 2012; BRICEÑO RUIZ, 2014) en el cual existieron posturas de Estados que criticaron fuertemente al neoliberalismo y propusieron agendas de gobierno alternativas. Independientemente de las distintas conceptualizaciones y caracterizaciones que existen en las investigaciones del período, nos interesa poder vislumbrar algunos de los conflictos que se sucedieron, las discusiones y tensiones, y los acuerdos. Las diferentes síntesis que proponen los conceptos de regionalismo postliberal (DA MOTTA VEIGA; RÍOS, 2007; SANAHUJA, 2012) post hegemónico (RIGGIROZZI; TUSSIE, 2012) o autónomo (MERINO, 2018), abonan a la idea de que lo que signó dicho período fueron los intentos -más o menos articulados entre los Estados suramericanospor construir desde un ámbito de concertación política como alternativa a la globalización neoliberal desde principios comunes de unidad regional y sin la injerencia extranjera. El nuevo siglo posibilitó condiciones para la articulación de agendas de integración que buscasen mayores grados de autonomía, soberanía y democracia.

Desde esta perspectiva analítica analizamos relaciones de poder, allí donde se combinan intereses estatales y corporativos que superan la escala nacional. Leerlos en tanto configuraciones amplias entre actores económicos, políticos, culturales y sociales, implica extender la mirada hacia los márgenes de la integración donde se encuentran ciertos actores no siempre visibles en instancias como las cumbres, pero presentes implícitamente (BARRENENGOA, 2019). Incorporamos fragmentos del material de entrevistas realizadas a distintos funcionarios y representantes políticos con roles específicos tanto en Brasil como en la UNASUR. La elección de las políticas del Estado brasileño y el recorte temporal que recorre los gobiernos de Luiz Inácio Lula da Silva (2003 - 2011) se corresponde con la existencia de una fuerte presencia brasileña en los procesos de integración suramericana reciente. Junto al diseño de una estrategia que buscó la expansión a partir de la región y su inserción internacional, las políticas para con la región suramericana fueron centrales (ZIBECHI, 2012). Esto fue así tanto en las primeras reuniones de presidentes suramericanos a principios de los años 2000, durante los gobiernos de Fernando Henrique Cardoso, como en los primeros antecedentes que tuvo la UNASUR con la Comunidad Sudamericana de Naciones (CSN). Examinamos las dinámicas integracionistas promovidas por los gobiernos lulistas y las tensiones que conllevó en la región suramericana. Con lo cual, el foco de esta investigación son las políticas implementadas desde Brasil en relación con la región suramericana para dar cuenta de las contradicciones y asimetrías que emergieron en su desenvolvimiento y relación con las clases dominantes. Asimismo, la indagación en las políticas del lulismo nos posibilita analizar lo que acontecía a nivel regional - particularmente en la UNASUR -, en un diálogo entre la escala nacional y la 
regional, en el que están presentes elementos propios del escenario internacional. Así arribamos a los tiempos recientes de crisis y parálisis del bloque, en sintonía con los cambios de gobierno en países como Brasil y Argentina.

\section{La política de expansión hacia la región}

La política exterior brasileña hacia Suramérica y otras zonas del mundo se erigió en un elemento clave para el desarrollo, desde una estrategia que buscaba la proyección de su poder en diferentes escalas. Entre los principales ejes en los que ésta se basó, el énfasis en la región suramericana fue un rasgo destacable del período. Anunciado por Lula da Silva en su discurso de asunción el 1 de enero de 2003, "La gran prioridad de política exterior durante mi gobierno será la construcción de una América del Sur políticamente estable, próspera y unida” (BRASIL, 2003). Caracterizada por los actores que la impulsaron como una política exterior “activa y altiva” (AMORIM; ROCHA, 2016), la presencia brasileña en los ámbitos, foros e instancias regionales e internacionales fue pensada como un modo de participar y generar nuevas demandas desde los países emergentes. Con la autonomía como idea vertebradora, se presentaban condiciones favorables para colocar a la periferia en un lugar de relevancia, a partir del proceso de integración entre los diferentes Estados.

Ahora bien, junto con la estrategia de política exterior brasileña existieron todo un conjunto de áreas estatales que fueron en dirección a promover el desarrollo desde un modelo de acumulación que priorizó a determinados sectores del empresariado brasileño, producto de la confluencia entre políticas públicas y política exterior (BERRINGER, 2015; IGLESIAS, 2008). Esto consolidó una estrategia de expansión de empresas y fortalecimiento de grupos económicos para la inversión en infraestructura y desarrollo, que tuvo a la región suramericana y a otras zonas del mundo como plataformas para su consecución. Es decir, como parte de la agenda de política exterior brasileña, la infraestructura fue una de las áreas que se constituyó en un objetivo estratégico compartido, primero con la Iniciativa para la Integración de la Infraestructura Regional de América del Sur (IIRSA) y luego con el Consejo Suramericano de Infraestructura y Planeamiento (COSIPLAN) de la UNASUR. En este sentido, vista desde el punto de viste del desarrollo económico comercial, la materialización de sus objetivos de crecimiento a partir del territorio suramericano confirió ventajas comerciales para Brasil en relación al resto de los Estados de la UNASUR (ZIBECHI, 2012). Asimismo, cuando se trató de la promoción de la infraestructura y la integración física regional como vehículo para el desarrollo económico regional desde inversiones estatales, también notamos un claro liderazgo por parte de Brasil (PADULA, 2010). Abordamos a continuación algunos de estos asuntos problemáticos desde una perspectiva multiescalar.

\section{Integración y desarrollo}

A pesar de que durante el primer gobierno de Lula da Silva la UNASUR no existía como tal, desde los inicios del nuevo siglo comenzaron las reuniones y los antecedentes previos a su surgimiento que encontraron en América del Sur un ámbito propicio para desarrollar una estrategia de integración que unificara la diversidad entre Estados. El activo interés por parte del Estado brasileño en la infraestructura conllevó la articulación de diferentes esferas que coincidieron la búsqueda de integración y el desarrollo regional. La integración física y particularmente la infraestructura se erigieron en aspectos centrales de la integración económica regional. Es decir, como medios para la materialización de objetivos más amplios de integración suramericana (WEGNER, 2018) e inscriptas en las dinámicas de desarrollo promovidas desde el Estado brasileño. Asimismo, vislumbramos estas estrategias de desarrollo a partir de la articulación entre política y economía, los ámbitos públicos y lo privado y desde la búsqueda de transformación de las estructuras productivas (ACTIS, 2011). Con lo cual, si bien identificamos antecedentes previos de iniciativas de integración como la IIRSA -del año 2000 las acciones tanto diplomáticas como gubernamentales para la integración suramericana no se profundizaron hasta iniciado el gobierno de Lula da Silva (PADULA, 2010). Esta estrategia colocó en un mismo nivel a la política exterior en 
relación a la inserción en Suramérica y a la inversión en infraestructura, que propició la colocación de empresas brasileñas en el mercado regional. La planificación del transporte y la integración energética involucraron a empresas proveedoras de bienes de capital, así como a los sectores más ligados a la construcción (IGLESIAS, 2008). Ahora bien, la consecución de estos objetivos generó contradicciones a la hora de hacer converger intereses disímiles y actores heterogéneos. Así, la proyección del poder brasileño generó efectos concretos sobre el resto de los países de la región. En el terreno de la integración física, existieron conflictos en torno a la infraestructura entre empresas brasileñas como Odebrecht y otros Estados, como Ecuador (ZIBECHI, 2012).

A escala local hay contradicciones. La Camargo Corrêa ha hecho una obra mal hecha en Ecuador y Ecuador demandó contra esa obra. Ahí cabe al país tener patrones de control sobre lo que está contratando. Hay contradicciones adicionales, eso existe. Repito, son relaciones que se dan en el marco del capitalismo. La integración también tiene una dimensión del capital (...). (ENTREVISTADO 1, 2017).

La estrategia de desarrollo y la política económica brasileña conllevó conflictos y resistencias con otros países suramericanos. Además de Ecuador, otro de los casos polémicos fue el de Bolivia, con la obra del TIPNIS (Territorio Indígena y Parque Nacional Isiboro-Secure). Ambos ejemplos ilustran las divergencias existentes entre actores gubernamentales, representantes del sector privado, del ámbito financiero, sectores productivos, empresas, poblaciones y movimientos sociales. Todas estas contradicciones se entramaron en el proceso de integración física generando, por un lado, la búsqueda del desarrollo y la expansión de las empresas brasileñas y por otro, conflictividades a nivel regional (BARRENENGOA, 2019).

A su vez, dentro del propio Brasil existieron a lo largo de este período tensiones en torno a los objetivos de integración regional y la relación que se iba tejiendo entre gobierno y empresas. En este sentido, el proceso de integración suramericano favoreció -por momentos- la confluencia entre actores empresariales y estatales. Como dijimos anteriormente, las políticas de los gobiernos lulistas fueron en favor del crecimiento y la expansión de determinados sectores del empresariado brasileño. En específico, las empresas de la industria de la construcción atravesaron un proceso creciente de expansión desde el año 1970, cuando dieron un salto y comenzaron a operar también fuera del territorio brasileño. Retomamos su conceptualización como "empresas de ingeniería", dado que se transformaron en multinacionales, por ser parte de las ramas más internacionalizadas, y abarcar una diversidad de servicios que van desde infraestructura, industria, energía, minería, servicios tecnológicos, hasta medio ambiente y minería (PEDREIRA CAMPOS, 2009). Un breve repaso histórico desde su origen nos muestra que, salvo durante el ciclo neoliberal en la década del '90, estas recorrieron un proceso ascendente de expansión, en países de Latinoamérica, América del Sur y África. Más adelante en el año 2008, a partir de la Política de Desarrollo Productivo (PDP), los objetivos de desarrollo pautados desde el Estado brasilero asumieron un carácter estratégico en relación a la integración con América Latina y África (BUSTELO, 2012; CERQUEIRA, 2014). De esta manera, esta expansión sirvió a los fines de la mejora de la posición de estas empresas a nivel nacional, regional e internacional, colocándolas como eslabones claves para que Brasil se proyectara a nivel mundial, tanto por tratarse de destinos consumidores, como receptores de inversión brasileña. Asimismo, las definiciones que fueron parte de la estrategia de desarrollo buscaron el crecimiento económico, la internacionalización y el financiamiento -a través del Banco Nacional de Desarrollo Económico y Social (BNDES), de gran parte de las iniciativas de integración regional que se promovieron (NOVOA, 2009).

La búsqueda de integración productiva en articulación con los países de la UNASUR incluyó también a los países africanos, con lo cual, la política exterior resultó ser inseparable de las políticas de desarrollo. Mientras aumentaba el liderazgo brasileño, apuntando a la internacionalización de empresas con capacidad competitiva en las áreas de infraestructura, energía y agroindustria, se profundizaba la estrategia de integración suramericana. A su vez, avanzaba el aprovechamiento de los recursos naturales y la especialización en industrias de commodities que serían las destinatarias de las inversiones brasileras (CERQUEIRA, 2014). Así, la región suramericana se encontró subsumida bajo dicha estrategia 
territorial que modificó el mapa económico comercial de América del Sur, ante el cual proliferaron críticas que marcaron la supremacía del gigante brasileño por sobre el resto de los países de la región (ZIBECHI, 2012).

En su “Carta ao Povo Brasileiro” Lula da Silva enviaba señales a sectores de las clases dominantes brasileñas buscando generar un amplio consenso social para su gobierno. En la misma, dirigida a los banqueros, al capital internacional, a los empresarios, les anunciaba que, durante su gobierno se realizaría una transición. Como consecuencia de las políticas de privatización y apertura comercial formuladas durante los gobiernos de Fernando Henrique Cardoso, las empresas atravesaron un proceso de desnacionalización y desindustrialización (BUSTELO, 2012). Los sectores más impactados fueron los provenientes de la industria, quienes vieron condicionado su potencial productivo y destruida su capacidad instalada (BERRINGER, 2015). Esto marcó la participación de estos grupos en las negociaciones en torno al ALCA y sus demandas en torno al financiamiento del BNDES para aumentar las exportaciones de sus productos (BERRINGER, 2015). Ahora bien, el hecho de que a determinados sectores del empresariado les favorecían las políticas de promoción del Estado brasileño no significa que irían a apoyar el ideario integracionista y mucho menos, la estrategia del gobierno del PT. Si analizamos estos actores en base a sus posicionamientos, relaciones e intereses en tanto actores sociales y no sólo a partir del lugar que ocupaban en la estructura productiva, podemos vislumbrar la materialización de sus intereses a través de ámbitos representativos como la Federación de Industrias del Estado de São Paulo (FIESP) y la Confederación Nacional de Industrias ( $\mathrm{CNI}$ ), junto con otros actores de las clases dominantes que expresaban a estos sectores en instancias públicas y privadas (BARRENENGOA, 2019). Así, la internacionalización de dichas empresas fue una política de Estado, con lo cual es posible resaltar como rasgo característico que, el crecimiento de empresas privadas fue producto de la confluencia entre políticas públicas y política exterior (BERRINGER, 2015; IGLESIAS, 2008). Esto consolidó una estrategia expansión de empresas y fortalecimiento de grupos económicos para la inversión en infraestructura y desarrollo, como se anunciaba en Plan de Aceleración del Crecimiento (PAC). El objetivo de consolidar la infraestructura regional se vinculó con la necesidad de reducir costos y aumentar la competitividad de los productos brasileros tanto en los mercados regionales como en los internacionales. A su vez, Brasil se incorporó a la IIRSA y al COSIPLAN confluyendo con una estrategia propia, combinando, también en este terreno, los planos de su política nacional, regional e internacional. Esto se observa, más explícitamente, en la incorporación de obras de la IIRSA en el PAC (CERQUEIRA, 2014; IGLESIAS, 2008). Como parte de esta estrategia mediante el uso obligatorio de recursos de empresas brasileñas -, el BNDES otorgaba créditos para financiar proyectos de infraestructura regional en el marco de la UNASUR. Esto daba a las empresas brasileñas importantes ventajas que les permitieron expandirse al ritmo del aumento de las divisas que el Estado acumulaba por las obras de infraestructura, mediante el pago de créditos en dólares, robusteciendo el mercado interno (BARRENENGOA, 2019). Como contracara de esto, el vínculo entre el Estado y las empresas fue también motivo de contradicciones.

La alianza entre sectores del empresariado brasileño y actores estatales se correspondió con relaciones previas construidas durante las negociaciones en torno al ALCA, donde diferentes sectores del empresariado participaron de las discusiones que decantaron en su rechazo. A esto se incorporaron sectores empresariales también de Argentina. Si bien, a lo largo de su historia, el vínculo entre Brasil y Argentina transitó distintos momentos, el nuevo contexto de regionalismo posibilitó el desarrollo de sus respectivas industrias, aunque, paradójicamente, inauguró nuevos conflictos entre sus clases dominantes, entre la reciprocidad y la competencia (PAIKIN, 2012). Las relaciones bilaterales no estuvieron exentas de tensiones también en este período.

Mercosur fue el principal vehículo de la integración, es la base de la UNASUR. Y el problema es que Itamaraty no acepta que Brasil abra más su soberanía. Entonces en la retórica de Brasil, en todos los países de América Latina, desde hace 200 años todos los gobiernos hablan de integración. Casi literalmente hablan de la misma cosa. Y había una idea de que como Néstor Kirchner se estaba acercando, y Uruguay, entonces algunas ideas iguales entre amigos, políticos, podía ser más fácil. De la misma forma en que Temer cree que con Macri va a ser más fácil. Pero no es así. Sobre todo, no fue así porque los dos gobiernos, después del desgaste del neoliberalismo, querían apostar a un reconstituir una base industrial. Entonces Argentina jamás podría aceptar las importaciones de Brasil y un déficit comercial crónico. Porque Brasil impone un déficit comercial a todos sus vecinos. Entonces era una 
esquizofrenia total. Cada vez que Argentina intentó defender sus intereses y salir del déficit con sus industrias, las empresas paulistanas, la burguesía brasilera reclamaba por el proteccionismo de Argentina. Entonces la burguesía no quería la integración, quería vender (ENTREVISTADO 2, 2017).

En la articulación entre los intereses de sectores de la burguesía y los objetivos de ampliación de la política exterior brasileña hacia América del Sur, podemos observar cómo la alianza con Argentina resultaba en un eslabón necesario. Como afirmaba un entrevistado, entre Argentina y Brasil existieron “contradicciones y coincidencias” (ENTREVISTADO 1, 2017). No obstante, existió una situación de déficit para Argentina en relación al comercio bilateral con Brasil, que muestra la desigualdad en la evolución de las estructuras productivas, presentando una ventaja en el sector de manufacturas de origen industrial, por parte de Brasil (BUSTELO, 2012; PAIKIN, 2012). Así, emergían las limitaciones provenientes de una estrategia de integración que no siempre encontraba reciprocidad.

De esta manera, en términos de modelos de desarrollo, política exterior y políticas de integración, las contradicciones emergieron en distintos planos. Estas no existieron sólo al nivel del capitalismo brasileño, sino que, los vínculos entre los Estados de la UNASUR estuvieron siempre atravesados por esta oscilación entre la unidad, la integración y la fragmentación. En el terreno económico florecieron disputas tanto al interior de Brasil como en relación a las relaciones asimétricas que su estrategia generaba para con el resto de los países. La estrategia de inversión y apoyo a capitales privados brasileños para su internacionalización (BRESSER - PEREIRA, 2013) y el uso de instrumentos públicos para ello, puso en evidencia las dimensiones de la economía brasileña en relación al resto de los países suramericanos. La conformación de conglomerados nacionales que pudiesen competir con grupos multinacionales, junto con los créditos para inversiones en capacidades productivas e infraestructura propiciaron la expansión del mercado interno y el desarrollo productivo (WEGNER, 2018). Esto hizo que Brasil se destacara del resto de los Estados, por su orientación hacia la integración de la infraestructura regional desde la aplicación de recursos considerables para ello y en un plano que excedió la región de América del Sur, involucrando otras regiones del mundo. Respecto de estas asimetrías y del liderazgo de Brasil en la región, mientras que algunos autores señalan las pretensiones imperiales (ZIBECHI, 2012), otros afirman que dicho liderazgo se encontraba con demasiadas limitaciones a la hora de asumir los costos que su posición implicaba en la práctica (DA MOTTA VEIGA; RÍOS, 2007). Esto explicaría por qué se trató más bien de un rol de liderazgo "blando" (SARAIVA, 2010). Más allá de esos debates, queda en evidencia la estrategia de expansión brasileña y el uso de instrumentos públicos como rasgo constitutivo de la misma, algo que también generaba contradicciones con las clases dominantes.

\section{Banco del Sur, soberanía y defensa}

Otra de las tensiones generadas al interior de la UNASUR fue a raíz del Banco del Sur. Como propuesta de integración económico financiera no pudo entrar en funcionamiento de manera formal por no haber sido aprobado de manera unánime por todos los parlamentos de los Estados de UNASUR. Uno de los aspectos que generaba controversia era la división entre los fondos que le tocaba aportar a cada Estado. Así, la visión de que el Estado brasileño intentó “vaciar” la propuesta” (MARINGONI; MEDEIROS, 2017, p. 43) provenía de las resistencias para aportar los fondos. Distintos factores de índole interna y externa nos sirven para comprender las causas de por qué no logró ponerse en marcha.

La participación de Brasil en el BRICS, a partir del año 2009 -participando de las reuniones desde 2006- mostraba los indicios de una alianza con China, lo cual le permitía impulsar un proceso de profundización del desarrollo desde políticas estatales (BUSTELO, 2012). Con lo cual, la pertenencia en simultáneo al Banco del BRICS complejizaba la participación brasileña en un banco suramericano. A su vez, la intensa actividad financiera del BNDES como agente financiador de las políticas económicas, de desarrollo y de infraestructura brasileñas y regionales hacía repensar el rol que tendría. Un banco de desarrollo con fondos regionales como el Banco del Sur podría haber servido a los fines de una estrategia de integración económica regional de largo plazo, equilibrando situaciones de desigualdad entre Estados e 
implicando otra dinámica del crecimiento e inversión (WEGNER, 2018). No obstante, el BNDES mostró mayor apoyo a proyectos locales que a obras de mayor envergadura, algo que desde el plano regional puede verse como un problema, en tanto su fuerte presencia terminó -de algún modo- opacando al Banco del Sur. A su vez, dadas las dimensiones de la economía brasileña y el volumen de financiamiento del banco, fueron inevitables las asimetrías en cuanto a las proporciones de aportes estatales esperadas para el Banco del Sur. De este modo, los representantes brasileños pretendían aportar una cifra menor en proporción al resto de los países del bloque, tomando como unidad de medida el PBI.

El Banco fue impulsado por Brasil, Argentina, Ecuador, Venezuela, Uruguay, Paraguay y Bolivia. Colombia, Perú y Chile no; Guyana y Surinam tampoco. Los aprobaron los parlamentos argentino, boliviano, uruguayo, ecuatoriano y venezolano. Sólo Bolivia y Uruguay querían aportar sus cuotas, mucho menores, de 2 billones de dólares. Argentina, Brasil y Venezuela eran los que más fondos ponían. Pero el BID y la CAF terminaron decidiendo todo. Actuaron contra el Banco del Sur siempre. (ENTREVISTADO 3, 2017).

A las limitaciones que introducía el entrevistado en cuanto a la injerencia de otros de los organismos financiadores de los proyectos regionales como la Corporación Andina de Fomento (CAF) y el Banco Interamericano de Desarrollo (BID), se incorporaban las situaciones políticas al interior de cada Estado miembro de la UNASUR. Esto complejizaba aún más el escenario no sólo en términos de contradicciones sino también en relación a los tiempos de aprobación, funcionamiento y puesta en marcha del mismo. De este modo, el Congreso brasileño nunca votó el Banco del Sur, lo cual aporta otro elemento explicativo vinculado con la dinámica política brasileña y el complejo entramado de su sistema político de partidos, algo que se agudizó en los gobiernos de Dilma Rousseff.

Una de las razones es la política exterior brasileña, ya que tiene que poner más cuota, pero a la hora de decidir su voto vale lo mismo que el de Suriname. A su vez, en términos de política interna Brasil está en un brete porque no hay consenso en su Congreso respecto de la agenda de integración. (...) En definitiva, hoy, el Banco del Sur es "papel mojado (ENTREVISTADA 4, 2016).

Independientemente de la situación política que asomaba en Brasil luego de los mandatos de Lula da Silva, las discusiones respecto de conformar o no un Banco suramericano abrían el juego a decisiones más estratégicas, vinculadas con rasgos estructurales de la región suramericana y sus Estados. En un plano, los posicionamientos diversos en relación a las potencias hegemónicas como EE.UU. y los instrumentos de integración que en simultáneo se promovían. Y en otro plano, las dificultades en torno a las reglas del consenso para avanzar en propuestas concretas para la UNASUR.

Acá se ve la disputa entre los países que vienen del MERCOSUR y los de la Alianza del Pacífico (línea Pacífico). El Consejo Suramericano de Economía y Finanzas es un parte aguas, y esto se ve previo a su conformación, desde el Grupo de Trabajo que avanzó mucho. Sin embargo, todo ese trabajo no termina por llevarse a la práctica, y en el contexto actual es muy difícil que tenga posibilidades reales de llevarse a cabo. Propuestas de un fondo anticíclico, de intercambio comercial en moneda local y no en dólares, y Banco de Desarrollo y Fomento -además del Banco del Sur. No se llega al consenso mínimo requerido para aprobarlo, que es nueve votos. Sí se tienen siete, lo cuales sería un antecedente importante para MERCOSUR, pero difícilmente para UNASUR." (ENTREVISTADA 4, 2016).

En este fragmento podemos recuperar emergentes de las contradicciones que tuvieron como telón de fondo las definiciones estatales en cuanto a la inserción internacional, los vínculos con otros organismos financiadores y otros bloques de peso en el mundo. La UNASUR no llegó a consolidarse al punto de construir bases comunes en materia de integración económica y financiera, ni del grado de acción que las estructuras estatales tendrían en esto. Tampoco existió consenso respecto del método un país, un voto, cuando los aportes económicos eran desiguales. En este sentido, Ecuador y Venezuela preveían un banco de desarrollo regional, con reservas de los Estados, y con un accionar bajo los objetivos públicos y no privados. Brasil no coincidía con la equiparación de voto y terminó aceptando bajo la condición de que su cuota sería menor en términos relativos. Si bien prevaleció la idea de que el banco debería tener una suscripción inicial de fondos públicos y luego captar recursos del sector privado, más semejantes a otros bancos privados, no terminó 
desarrollándose como un instrumento para la integración. Y podemos agregar otra complejidad en este aspecto que es que, en el caso de Brasil, la inversión pública siguió siendo capturada también por parte del sector financiero (BARRENENGOA, 2019). Aquí se abre un asunto por demás complejo en torno a la financierización de las economías suramericanas y su relación el capitalismo internacional.

De esta manera, encontramos una multiplicidad de factores explicativos que emergen en el análisis de las contradicciones propias del proceso de integración suramericana, de las cuales podemos derivar las dificultades en torno a compartir una visión estratégica común respecto de los objetivos de la UNASUR. Algunos provinieron de la divergencia en torno a los intereses de grupos empresariales interesados en colocar sus productos en la región, que competían entre sí, como sectores de las burguesías argentina y brasileña. No obstante, estos no alcanzan por sí solos para comprender el entramado de relaciones y conflictos que se tejieron. Por lo cual, circunscribimos los matices en un marco histórico, político e inclusive ideológico y cultural. Desde sus antecedentes, en el proceso de conformación de la UNASUR, convivieron posturas muy diferentes en materia de integración económica y financiera, y limitaciones previas de los diferentes países.

Asimismo, es preciso recuperar la dinámica de cambios que se fueron produciendo a nivel regional que impactarían en la reorientación de las políticas de integración que se promovieron durante los primeros años de la UNASUR. Este período se caracterizó por importantes núcleos de decisiones que la región tomó, distinguibles por el conjunto de países y líderes que las empujaba, y respondiendo a modalidades de integración enfocadas en consolidar el bloque desde una perspectiva político institucional (COMINI; FRENKEL, 2014). Así, esta primera etapa estuvo mediada por la mayor influencia de aquellas estrategias destinadas a pensar la recomposición de los Estados suramericanos junto con su desarrollo conjunto. No obstante, tomando las particularidades de UNASUR notamos que su propia estructura institucional de funcionamiento llegó a convertirse en un límite para la toma de decisiones, dadas las reglas de funcionamiento donde un país era igual a un voto, -independientemente de los desproporcionados aportes económico financieros.

Ahora bien, el desarrollo que por esos años tuvo el Consejo de Defensa de la UNASUR posibilitado por la coyuntura, nos indica que fueron momentos propicios para el avance de una estrategia con mayores grados de autonomía relativa, desde una narrativa de diálogo y cooperación entre Estados. Cuando se trató de sostener las democracias y defender la soberanía de los Estados suramericanos, se consiguió el consenso de los doce Estados para la resolución de conflictos y crisis sin la intervención de actores ni organismos extra regionales, desde estrategias conjuntas de institucionalización y de acción ante conflictos que los involucraban. Podemos mencionar el conflicto entre Colombia y Venezuela por las FARC (2010), la "Masacre de Pando" en Bolivia (2008), el Golpe de Estado en Honduras, en junio de 2009, entre otros intentos desestabilizadores. También la presencia de bases norteamericanas en Colombia que dio lugar a la Cumbre de UNASUR en Bariloche (2009), y el golpe de Estado en Paraguay (2012). Salvo en este último caso, en el resto, las intervenciones de los Jefes de Estado desde la UNASUR lograron frenar los conflictos a partir de un posicionamiento unificado como bloque. En julio de 2009, el presidente de Colombia Álvaro Uribe anunció intenciones de firmar un Acuerdo de Cooperación Técnica con EE.UU., que habilitaba a este a hacer uso de siete bases militares en territorio colombiano. En respuesta a este conflicto, los Estados miembros de la UNASUR reunidos en Bariloche establecieron una "Zona de Paz", resaltando el principio de solución pacífica de los conflictos, sin la intervención de potencias extranjeras que pudiesen amenazar la estabilidad de la región (BARRENENGOA, 2019). Un aspecto relevante del CDS fue el hecho de romper con la tradición que tenía a EE.UU., tutelando la defensa de la región y, por ende, presente en todas las herramientas que se impulsaban (SOARES DE LIMA, 2013).

Como parte de la política exterior brasileña, la dimensión del desarrollo convergió con la defensa, puesto que en su Estrategia de Defensa Nacional del año 2008 estos se planteaban como pares indisociables, lo cual involucraba a múltiples actores provenientes de los ámbitos públicos y privado (BARRENENGOA, 2019). Así, la integración de América del Sur ocupó un lugar destacado en la Estrategia de Defensa Nacional (EDN) de manera previa al surgimiento del CDS, 
impulsado también por los Ministros de Relaciones Exteriores Celso Amorim y de Defensa Nelson Jobim. Así, se enfatizaban como aspectos centrales el estímulo a la integración suramericana en aras de contribuir a la cooperación militar regional, integrar las bases industriales, defender los recursos y llegar al océano Pacífico desde corredores comerciales (ZIBECHI, 2012).

Como observamos, en todos estos momentos de alta conflictividad, hubo presencia de intereses norteamericanos, con lo cual, la defensa de una postura autónoma ante estos tuvo su correlato no sólo en iniciativas como la UNASUR, sino también en la participación activa en organismos multilaterales. Esto generó grandes conflictos dentro de Brasil y en el resto de los países de la UNASUR. Las presiones que los distintos actores de las clases dominantes brasileras recibían para abandonar su estrategia para con la región suramericana son una muestra de ello. Este fragmento y declaración de un ex Director de Inteligencia Nacional durante el gobierno de Obama, el retirado Teniente General James Clapper, ilustra la amenaza que el clima de unidad generaba para los Estados Unidos;

Los esfuerzos regionales que reducen la influencia de EE.UU. están ganando algo de tracción. Se planifica la creación de una comunidad de América Latina y el Caribe, prevista para inaugurarse en Caracas en julio, que excluye a EE.UU. y a Canadá. Organizaciones como la UNASUR están asumiendo problemas que fueron del ámbito de la OEA. En efecto, los países de América del Sur, con una o dos excepciones, cada vez más están recurriendo a la UNASUR para resolver los conflictos o disturbios en la región (...). El éxito económico de Brasil y la estabilidad política lo han puesto en la senda del liderazgo regional. Brasilia es probable que continúe usando esa influencia para enfatizar UNASUR como el primer nivel de seguridad y mecanismo de resolución de conflictos en la región, a expensas de la OEA y de la cooperación bilateral con los Estados Unidos. También se encargará de aprovechar la Organización para presentar un frente común contra Washington en asuntos políticos y de seguridad regionales (CLAPPER, 2011 apud BARRENENGOA, 2019, p. 95).

Para concluir, la política regional de defensa de la CDS se erigió en una especie de paraguas institucional que funcionó como base para la defensa de las democracias suramericanas en momentos críticos. Asimismo, para el propio Estado brasileño esta fue clave en su política exterior, motivo por el cual tuvo una presencia activa en el Consejo suramericano, además de la reivindicación de su lugar en el Consejo de Seguridad de la ONU junto con Argentina. La confluencia de liderazgos regionales que se caracterizaron por construir repertorios de acción interestatales comunes de cara a una concepción multidimensional de la integración permitió avanzar en la consecución de estos objetivos. Contraponiendo a la crisis instancias de articulación regional, propusieron un esquema de resolución internos de los conflictos desde el establecimiento de mínimos denominadores comunes, muchos de ellos expresados en la proliferación de Consejos Ministeriales, Planes Estratégicos, áreas de trabajo y agendas regionales. No obstante, una mirada de estas herramientas institucionales desde su continuidad en el tiempo muestra que fueron insuficientes para sostener el bloque de UNASUR cuando las correlaciones de fuerzas políticas cambiaron en algunos de los Estados suramericanos.

\section{Contradicciones emergentes desde un análisis multiescalar}

Lejos de tratarse de un bloque homogéneo, la UNASUR fue, desde su constitución, una concertación política entre actores diversos que logró la unificación de acciones concretas de gran relevancia para la región. Ante un nuevo marco de regionalismo suramericano, se abrieron condiciones para la emergencia de coaliciones de gobierno y fuerzas sociales que buscaron alternativas al neoliberalismo desde proyectos de desarrollo diferentes entre sí. Ahora bien, entre algunos de los elementos que aportaron en la fragmentación regional y la crisis final de UNASUR, se encuentran las desigualdades estructurales que existían - y que persistieron- entre los doce Estados que la conformaban. A su vez, al nivel de las relaciones políticas de fuerzas en cada país también emergieron cambios que perjudicaron el consenso regional conseguido en principio y que pusieron en evidencia las diferencias en cuanto a las posturas de inserción internacional. Tanto al interior del bloque de la UNASUR como hacia dentro de la formación social brasileña - en el plano de los funcionarios estatales y en relación a las clases dominantes -, se fueron desarrollando contradicciones que fueron desdibujando la idea 
inicial de unidad que signó el período de regionalismo. En la reconstrucción de algunas de estas tensiones que se sucedieron en el período, intercalamos las escalas nacional, regional e internacional.

En el caso brasileño, indicamos que las políticas de integración regional en relación a América del Sur ya eran parte del ideario diplomático en gobiernos previos. La política exterior desde ese entonces ya planteaba la oposición al NAFTA y al incipiente ALCA, proponiendo el Acuerdo de Libre Comercio de América del Sur (ALCSA). No obstante, existió un giro sustancial en la estrategia, respecto de los gobiernos de Fernando Henrique Cardoso, notable a partir de diferentes aspectos (BERRINGER, 2015). Uno de ellos, fue el cuestionamiento al rol de EE.UU. en la región y a la hegemonía neoliberal. Otro, fue la tradición nacionalista, desarrollista y en favor de la integración regional de quienes ocuparon en ese entonces el palacio de Itamaraty; personificados en las figuras del Canciller Celso Amorim y el Secretario Gral. Samuel Pinheiro Guimarães. Durante los gobiernos de FHC se consolidó una corriente institucionalista pragmática en Itamaraty, que luego se enfrentó a las ideas autonomistas que predominaron durante los gobiernos lulistas (MÍGUEZ, 2017). Si bien dentro de ambas corrientes había tendencias y matices, a grandes rasgos podemos ubicar aquellos funcionarios provenientes de una tradición más autonomista en materia de relaciones internacionales, otros de una más realista, otros institucionalistas, y algunos más socialdemócratas (SARAIVA, 2010; BARRENENGOA, 2019). De una política exterior subordinada a los poderes imperiales se pasó a una de "subordinación conflictiva” (BERRINGER, 2015, p. 104), que buscó equilibrar el histórico peso norteamericano en los asuntos latinoamericanos, lo cual tuvo costos significativos. La política exterior se constituyó en uno de los pilares de la estrategia de los gobiernos de Lula, involucrando no sólo las agendas de desarrollo económico y de relaciones internacionales sino también a sectores de la sociedad brasileña desde una fuerte y abarcadora participación estatal. Los sectores opositores criticaron esto señalando la "partidización” de la agenda de política exterior (BARBOSA, 2015), algo que fue subrayado por el propio gobierno como el camino necesario para la proyección de su poder a niveles regional e internacional. Estos encontraron eco en las clases dominantes brasileñas y terminaron articulándose como un bloque opositor, en el marco de disputas nacionales que tuvieron su correlato final en la destitución de Rousseff. De manera paradojal, el lulismo en el gobierno creó oportunidades para múltiples actores que iban más allá del Palacio de Itamaraty, en una suerte de pluralización de los actores de la política exterior que fueron articulados a nivel interno y externo (GIACCAGLIA, 2010; MÍGUEZ, 2017). Con participación activa en los debates previos al rechazo al ALCA, varios de los ámbitos en los que se encontraban representados los intereses de sectores del empresariado brasileño, como la CNI y la Coalición Empresarial Brasilera (CEB) sostuvieron su presencia en las negociaciones internacionales. Estos sectores lograron acrecentar su lugar en las instancias de definición de estrategias de inserción internacional (GIACCAGLIA, 2010). De este modo, observamos aquí una clara vinculación entre sectores del empresariado con sectores del Itamaraty y del propio gobierno. Como resultado de la incidencia de los intereses de sectores de la construcción civil, energía, alimentos y otros vinculados al comercio de exportación, se creó con ellos el Consejo Empresarial Brasil- China (CEBC) (BERRINGER, 2015). Ante condiciones favorables para la economía brasileña y su posición como jugador global en el escenario internacional, el Estado profundizó el acercamiento también hacia otros actores geopolíticos. Por lo cual, a los ejes de la agenda de política exterior, como la integración regional y la defensa de los intereses nacionales, se incorporaron el diálogo con otros Estados y zonas periféricas, la búsqueda de expansión comercial, la participación e intervención en las instituciones como el FMI, el Banco Mundial, el Consejo de Seguridad de la ONU, la Organización Mundial del Comercio, y el G20, entre otros (MÍGUEZ; CRIVELLI, 2014). En muchos casos, Brasil junto con Argentina lograron cierto juego político y diplomático en ámbitos internacionales de gran peso y visibilidad. Esto se explica porque la prioridad de integración suramericana fue inscripta en un objetivo mayor de Cooperación Sur-Sur, en sintonía con las transformaciones que estaban aconteciendo a nivel internacional en dirección a una multipolaridad relativa, conferida por cierto debilitamiento del poder unipolar estadounidense (MERINO, 2016), el acercamiento a China y el giro hacia Asia Pacífico (MÍGUEZ; CRIVELLI, 2014). 
Ahora bien, algunos lineamientos de la política exterior como la apertura a otras zonas del mundo generaron contradicciones hacia dentro de Brasil con diferentes actores de las clases dominantes. La consideración de una "mentalidad de sustitución de importaciones" fue fuertemente criticada desde sectores económicos de gran peso, que veían en las políticas proteccionistas una amenaza a los principios de la libre competencia. Específicamente, la importación de productos chinos afectó a sectores de la industria local que la FIESP representaba, motivo suficiente para que se opusieran al proteccionismo en las compras públicas, con contenido local y reclamaran una política cambiaria favorable a la industria de transformación local (BOITO; 2017). Asimismo, la articulación con otros actores internacionales, la participación en el BRICS y la alianza estratégica con China fueron vistos con recelo por parte de actores de las clases dominantes brasileñas que presionaban por reorientar la política exterior hacia el norte. Esto marcó, en algunos casos, diferencias dentro del bloque que contribuyeron en la fragmentación y posterior freno en el proceso de integración regional promovidas desde la UNASUR. Con estas transiciones como telón de fondo, la estrategia de política exterior del gobierno de Lula, buscó ampliar el margen de maniobra apoyándose en Suramérica y expandiendo sectores claves de su economía que se beneficiaron de esta. Sin embargo, el creciente protagonismo que los sectores empresarios y corporativos fueron adquiriendo en las decisiones de política nacional e internacional terminó por generar conflictos que terminaron de materializarse con el final del ciclo de los gobiernos del PT hacia el año 2016 (MÍGUEZ, 2017). No siempre la relación Estado- empresarios fue expresión de estrategias compartidas, sino, por el contrario, esta se encontró con límites estructurales que pusieron al proyecto político del PT en jaque durante los gobiernos de Rousseff hasta su destitución. A nivel regional las contradicciones comenzaron a agudizarse a medida que el mapa político regional se iba transformando junto con los efectos de la crisis financiera global y su simultaneidad con distintos procesos que persisten hasta la crisis actual.

\section{Desaceleramiento y crisis}

Distintos eventos se fueron sucediendo a partir del año 2011, que generaron que UNASUR pierda potencia hasta su situación de crisis actual, detenida en sus funciones y vaciada en sus membresías. Existen una multiplicidad de factores que tienden a explicar esto, con lo cual, explicitaremos sólo algunos, comenzando por mencionar la crisis financiera global que repercutió en el año 2009 en el comercio intrarregional (BUSTELO, 2012; PAIKIN, 2012). En un contexto que empezó a mostrar cada vez mayores dificultades para el sostenimiento de proyectos regionales como el de la UNASUR, el peso de los liderazgos presidenciales y el consenso como método para la toma de decisiones se convirtieron en aspectos de debilidad para la continuidad del bloque. Asimismo, los conflictos al interior de los Estados que se arrastraron desde los intentos desestabilizadores y golpes de Estado en Paraguay, Ecuador y Bolivia, junto con la destitución de Dilma Rousseff, meses posteriores a su reelección.

En este marco, se abrió el juego a una nueva estrategia en crecimiento que inauguró la posibilidad de nuevos acuerdos en pos de priorizar los vínculos con actores globales y posibilidades de integración en distintas escalas (COMINI; FRENKEL, 2014), cuyo ejemplo más cabal es la Alianza del Pacífico. El método de consenso plasmado en su Tratado Constitutivo fue una muestra de solidez institucional cuando el bloque funcionaba con grados mínimos de acuerdo, pero en cuanto las relaciones de fuerza política fueron cambiando, este se volvió un obstáculo para los países de la región. Con el cambio de las agendas de política exterior de algunos de sus Estados miembro -como Brasil, Argentina y Ecuador-, las políticas regionales respondieron a distintos preceptos y emergieron nuevos actores, visibles en la reorientación del MERCOSUR (y el consiguiente acuerdo MERCOSUR- UE, el condicionamiento a Venezuela y la salida de la UNASUR (SIMONOFF, 2019). Al ser un organismo intergubernamental dependiente del devenir de cierto presidencialismo predominante, los efectos de hechos como la repentina muerte de Néstor Kirchner en 2010, seguida de la de Hugo Chávez en 2013, junto con los conflictos en la política nacional brasileña que emergieron en el segundo gobierno de Dilma Rousseff, 
fueron expresiones significativas del inicio del proceso de desaceleración y debilitamiento del bloque. Con una fuerte impronta política y dada su sujeción a los constantes recambios en las correlaciones de fuerzas al interior de los Estados, las coyunturas nacionales que los atravesaron contribuyeron en la pérdida de peso del organismo regional, dado cierto repliegue de los gobiernos hacia el interior de sus territorios.

A su vez, a tono con las transformaciones que fueron aconteciendo en el plano internacional, el acercamiento de China a nuestra región y la política exterior brasileña en relación a otras zonas del mundo, generaron resistencias en actores locales y extra regionales que alertaron sobre los impactos de la misma para con EE.UU. En el caso brasileño, generar alianzas y acuerdos en los planos diplomáticos, pero también económicos con países emergentes era visto como un cambio de prioridades. La Cooperación Sur-Sur y las políticas de integración suramericanas tuvieron sectores opositores que intentaron re direccionar la política exterior, por considerarla ideologizada. Este rasgo emergió con cada vez mayor fuerza en los discursos de los líderes que surgieron con posterioridad a los gobiernos lulistas, en tanto legitimación de sus nuevas agendas de política exterior, en su realineamiento con EE.UU., en detrimento de otras zonas del mundo. Así, fue notable el giro en las políticas de integración y en la agenda de política exterior brasileña desde la destitución de Rousseff (MERINO, 2018). Asimismo, los rumbos que países como Perú, Chile y Colombia asumieron, junto con el giro hacia Asia Pacífico, hicieron que ya no se lograra el nivel de consenso que le permitió en sus inicios a la UNASUR, ser un paraguas de concertación política que funcionaba con bases y acuerdos comunes. De esta manera, las divergencias persistentes en las agendas de integración muestran la oscilación entre el Atlántico y el Pacífico y los nuevos atractivos que otros bloques y actores internacionales generaron, deterioraron el proceso suramericano. La sostenibilidad de los procesos de integración en el tiempo reflejó una dinámica que terminó resultando muy frágil en términos institucionales. En 2014 ocurrió la última reunión de Jefes y Jefas de Estado de la UNASUR. Desde ese entonces, entre la falta de funcionario que ocupase -con consenso- la Secretaría General y el desgranamiento de sus miembros a partir de los cambios de gobierno, no volvió a actuar en el escenario regional como bloque, más allá de la inercia institucional de algunos de sus Consejos Ministeriales.

A partir del año 2015 la política regional se ha visto marcada por un mayor acercamiento a EE.UU., con la promoción de políticas neoliberales y represivas. Vislumbramos un nuevo mapa regional en el que fueron puestas en cuestión las propuestas de integración generadas a comienzo de siglo para abrir paso al avance del modelo de acumulación neoliberal en países como Brasil y Argentina. En este sentido, el acercamiento a la Alianza del Pacífico de los gobiernos de Macri y Temer constituyó una señal de giro en la política exterior de ambos países, sobre todo económica y comercial, más que un efecto concreto en el corto plazo (SIMONOFF, 2019). Estos cambios trajeron aparejadas nuevas alianzas políticas y marcos de integración regional acordes a la nueva coyuntura. A su vez, significaron la búsqueda de realineamiento con EE.UU. en detrimento de la integración regional y la Cooperación Sur - Sur. Como corolario, impactó en la reorientación del MERCOSUR, el fortalecimiento de la Alianza del Pacífico, el lanzamiento de nuevos tratados de libre comercio y la suspensión de la UNASUR y la CELAC en el escenario regional.

Para el año 2019 habiéndose retirado de la UNASUR, los presidentes de Brasil, Chile, Argentina, Colombia, Perú, Paraguay, Guyana y Ecuador convocaron el Foro para el Progreso de América del Sur (SANAHUJA, 2019). Paulatinamente, la UNASUR pasó de ser una herramienta política para la defensa de la autonomía y democracia a un organismo etiquetado como ideológico por parte de los líderes que convocaron a la reunión del Prosur. Con la elección de Jair Bolsonaro se concretó el abrupto viraje de la política exterior brasileña alineada con los EE.UU. de Donald Trump y quedo más al descubierto la situación de fragmentación regional. El mayor acercamiento a Washington por parte de la mayoría de los Estados latinoamericanos -observado con mayor claridad en los casos de Brasil y Argentina-, se observó también en el monitoreo norteamericano en torno a la agenda de seguridad. Esto se observa también en el terreno económico, retornando con mayor fuerza las políticas de endeudamiento, desregulación y apertura comercial (SIMONOFF, 2019). 
En síntesis, las políticas de integración regional que aquí se han mencionado -con sus matices y contradicciones, se encontraron en los últimos cinco años con giros abruptos, producto de la irrupción de nuevos actores y relaciones de fuerza en los distintos Estados miembro, con los respectivos cambios en sus agendas de política exterior y la parálisis de la UNASUR.

\section{Consideraciones finales}

En este artículo nos propusimos recomponer algunas de las contradicciones que acompañaron el proceso de constitución y desarrollo de la UNASUR desde el análisis del rol brasileño allí. Afirmamos que desde sus inicios este ha sido un organismo atravesado por dinámicas conflictivas y contradictorias. Al estar estrechamente vinculadas la política exterior brasileña con su estrategia de desarrollo, cuando se acentuaron las contradicciones vinculadas a esta, hubo un desaceleramiento de su participación en instancias regionales que cobró mayor notoriedad con el gobierno de Temer. Posteriormente, con el gobierno de Bolsonaro termina por quedar en evidencia el abrupto viraje de su política exterior.

En las áreas de comercio, infraestructura y finanzas, recorrimos algunas de las contradicciones que pusieron de manifiesto ciertas asimetrías entre Brasil y el resto de los países, dadas por el impulso al desarrollo desde instrumentos públicos como el BNDES y el apoyo a grupos empresariales que se expandieron a partir de la región suramericana. Las tensiones recorrieron los vínculos bilaterales y las divergencias entre sectores del empresariado argentino y brasileño, y emergieron en los conflictos por obras de infraestructura en países como Ecuador y Bolivia. Estas también habitaron al interior del propio Brasil, en el vínculo que Estado y empresas tuvieron durante los gobiernos lulistas.

La UNASUR fue partícipe de dinámicas que oscilaron entre la unidad y la concertación política, desbordando las tradicionales propuestas de integración comercial y la fragmentación mayormente visible en los últimos años, hasta su parálisis final. Sin embargo, esta condición no le impidió al bloque conseguir ciertos grados de autonomía en circunstancias donde estaba en juego la democracia de alguno de sus Estados. La actuación de la UNASUR puso de manifiesto la capacidad de los países suramericanos de resolver los conflictos y crisis de manera autónoma y democrática, sin la intervención de organismos y países extra regionales; lo cual desdibujó el histórico rol de la OEA. Este proceder favoreció instancias de defensa de la soberanía a partir de un organismo regional y legítimo, prescindiendo de otros actores extrarregionales. Con lo cual, uno de los logros de esta asociación regional suramericana fue el de establecer el diálogo, la cooperación y los vínculos entre los Estados, así como la defensa de principios como el de soberanía y autodeterminación. Esto se dio en momentos de reestructuración del poder estatal para los cuales la UNASUR resultó en un ámbito facilitador para la recomposición del rol político estratégico de los Estados Nación, en relación a mayores grados de autonomía, y en contraposición al neoliberalismo.

Lo inédito del Consejo de Defensa Suramericano fue que inauguró la posibilidad de pensar la defensa desde la propia región, sin injerencia extranjera. Para lo cual, las políticas de cooperación Sur - Sur y las transformaciones internacionales contribuyeron en las nuevas alianzas que se tejieron entre zonas periféricas. Existió cierta coincidencia entre los distintos actores internacionales en torno al aprovechamiento de las oportunidades que el contexto de multipolaridad relativa brindaba. Para la región suramericana, este proceso tuvo una impronta clara en torno a la consolidación de la democracia y la defensa de la soberanía que los Estados - en conjunto- consiguieron. Como contracara, actores políticos y de las clases dominantes buscaron torcer la balanza por realinear las agendas de política exterior en dirección al norte.

También vimos que las contradicciones que generaron ciertas asimetrías en el bloque se vincularon con la dimensión económico financiera de la integración, terreno en el cual afloraron con mayor crudeza las desigualdades estructurales entre los países y las divergencias en torno a las visiones estratégicas de la integración. 
Por otro lado, los mecanismos de toma de decisiones resultaron en una traba para la consecución de objetivos que la UNASUR se planteaba, algo que limitó un funcionamiento más ágil del bloque. Cuando el clima político regional comenzó a cambiar desde los acontecimientos sucedidos en Brasil y Argentina -inicialmente-, la institucionalidad de la UNASUR comenzó a fragilizarse por fuerza de nuevas alianzas regionales. En este sentido, la reconfiguración del entramado político brasileño hasta la destitución del gobierno de Rousseff, junto con los cambios de gobierno en Argentina y Ecuador, junto con la crisis en Venezuela, se constituyeron en factores de peso y desequilibrio para toda la región. A este proceso de cambios lo acompañaron nuevos lineamientos en la política regional que buscaron la conformación y el regreso a un área de integración económico- comercial favorable a políticas de liberalización, atracción de inversiones y financiamiento externo desde políticas aperturistas ante los mercados internacionales, algo visible en el acuerdo MERCOSUR- UE y en la propia reorientación del MERCOSUR, con el condicionamiento a Venezuela.

Por último, la actual pandemia del COVID - 19 pone al descubierto, con mayor fuerza, la situación fragmentación regional a la que ya veníamos asistiendo como región y agudiza la crisis sanitaria, social y económica.

\section{Referências}

ACTIS, Esteban. La estrategia "híbrida" de desarrollo del gobierno de Lula: neodesarrollismo heterodoxo. Temas y debates, n.22, p. 115-135, Rosario dic. 2011

AMORIM, Celso; ROCHA, Antonio Jorge Ramalho (Eds). A grande estrategia do Brasil: discursos, artigos e entrevistas da gestao no Ministerio da Defesa (2011-2014). Brasilia: Fundación Alexandre de Gusmão, Editora Unesp, 2016.

BARRENENGOA, Amanda. ¿Mudar para valer?: Estado y clases dominantes en los entramados de la integración suramericana: Brasil en el COSIPLAN-UNASUR (2003-2011). Tesis de Doctorado en Cs. Sociales. Universidad Nacional de La Plata. Facultad de Humanidades y Ciencias de la Educación, 2019, En línea:<http://sedici.unlp.edu.ar/handle/10915/77918>. Acceso el 30 nov. 2018.

BARBOSA, Rubens. "FHC e Lula, políticas externas divergentes", Instituto Teotônio Vilela, PSDB (Partido da Social Democracia Brasileira). 2/12/2015. En línea: http://itv.org.br/opiniao/ldquofhc-e-lula-politicas-externas-divergentesrdquo-por-rubens-barbosa. Acceso el 30 nov. 2018.

BERRINGER, Tatiana. A burguesía brasileira e a política externa nos governos FHC e Lula. Curitibia: Appris, 2015.

BOITO, Armando. “O legado dos governos do PT”. En Maringoni Gilberto, Medeiros Juliano. Cinco mil días: o Brasil na era do Lulismo. São Paulo: Boitempo/Fundaçao Lauro Campos, 2017.

BRASIL. En: Presidencia da Republica. Discurso de posse do presidente Luiz Inacio Lula Da Silva: Brasilia. 2003. En línea: $<$ http://www.biblioteca.presidencia.gov.br/presidencia/ex-presidentes/luiz-inacio-lula-da-silva/discursos/discursos-deposse/discurso-de-posse-1o-mandato/view>. Acceso 2 mai. 2020.

BRESSER- PEREIRA, Luiz C. Empresários, o governo do PT e o Desenvolvimentismo, Revista de Sociología Política, v.21, n.47, p. 21-29, 2013.

BRICEÑO RUIZ, José. “Del Regionalismo Abierto al Regionalismo Poshegemónico en América Latina”. Política Internacional e Integración Regional Comparada en América Latina. San José (Costa Rica): Willy Soto Acosta Editor-FLACSO, p. 23-34, 2014.

BUSTELO, Santiago. Desenvolvimento e políticas industriais: um estudo comparativo entre a Argentina e o Brasil (2002-2008) (Dissertação de Mestrado). Universidade Federal do Río de Janeiro. Instituto de Economía, 2012.

CERQUEIRA FRANCO, Daniela. Brasil en el proceso de integración con América del sur: una política destinada a consolidar la lógica de acumulación del capital. XIV Jornadas de Economía Crítica, España, 2014.

COMINI Nicolás; FRENKEL Alejandro. Una Unasur de baja intensidad. Modelos en pugna y desaceleración del proceso de integración en América del Sur. Nueva Sociedad, n.250, p. 58-77, 2014.

DECIANCIO, Melisa.; MÍGUEZ M. Cecilia. Contribuciones de los estudios globales al análisis de la política exterior: una aproximación metodológica". Colombia Internacional, n.102, p. 87-112, 2020. En línea: <https://doi.org/10.7440/colombiaint102.2020.05>. Acceso el 2 mai. 2020.

GIACCAGLIA, Clarisa. La influencia de los actores domésticos en la política exterior brasileña durante el gobierno de Lula da Silva. Confines, v.6, n.12, p. 95-121, agosto-diciembre, 2010.

SARAIVA, Miriam Gomes. A diplomacia brasileira e as visões sobre a inserção externa do Brasil: institucionalismo pragmático x autonomistas (ARI). Mural Internacional, v.1, n.1, 2010. 
IGLESIAS, Roberto. "Algunos elementos para caracterizar los intereses brasileros en la integración de la infraestructura de América del Sur”. Integración y Comercio, n² 28 (12) pp. 161-190, 2008. Instituto para la integración de América Latina y el Caribe, Bs. As.

KAN, Julián. La integración desde arriba. Los empresarios argentinos frente al MERCOSUR y el ALCA. 1a Ediciones Imago Mundi. Buenos Aires, 2015.

KAN, Julián; PASCUAL, Rodrigo. Integrados (?). Debates sobre las relaciones internacionales y la integración regional latinoamericana y europea. Buenos Aires: Imago Mundi, 2013.

KATZ, Claudio. El rediseño de América Latina: ALCA, MERCOSUR y ALBA. 1a Ed. Buenos Aires, Luxemburg, 2006.

DA MOTTA VEIGA, Pedro; RÍOS, Sandra. O regionalismo post-liberal na América do Sul: origens, iniciativas e dilemas. CEPAL, Serie Comercio Internacional, n.82, p. 3-48, 2007.

MARINGONI, Gilberto.; MEDEIROS, Juliano. Cinco mil días: o Brasil na era do Lulismo. 1ed. São Paulo: Boitempo. Fundaçao Lauro Campos, 2017.

MERINO, Gabriel. Tensiones mundiales, multipolaridad relativa y bloques de poder en una nueva fase de la crisis del orden mundial. Perspectivas para América Latina, Geopolítica(s) Revista de estudios sobre espacio y poder, v.7, n.2, p. 201-225, 2016.

MERINO, Gabriel. Del apogeo "lulista” a la destitución de Dilma. El devenir popular neodesarrollista en Brasil. Latinoamérica. Revista de Estudios Latinoamericanos, n.66, p. 223- 259. UNAM, México, enero 2018.

MÍGUEZ, M. Cecilia. Política interna y política exterior en el regionalismo del siglo XXI: conflictos políticos y crisis del MERCOSUR en el Brasil reciente, Informe Integrar, n.101, p. 2-22, La Plata, febrero 2017.

MÍGUEZ M. Cecilia; CRIVELLI Agustín. El Brasil actual: entre viejos y nuevos roles y socios. Realidad Económica. IDAES, Buenos Aires, 2014 p. $65-95,2014$

MORGENFELD, Leandro. Argentina y América Latina ante un histórico dilema: unidos o dominados. Rebela Revista Brasilera de Estudios Latinoamericanos. v.1, n.1, p. 10-37, 2011.

NOVOA, Luis. O Brasil e seu “desbordamento": o papel central do BNDES na expansão das empresas transnacionais brasileiras na América do Sul. Empresas transnacionais brasileiras na América Latina: um debate necessário. Instituto Rosa Luxemburg Stifung. São Paulo Expressão Popular, p. 187- 204, 2009.

PAIKIN, Damián. Integración productiva y desarrollo regional: tensiones en el marco de la crisis global. Aportes para la Integración Latinoamericana, v.18, n.2, p. 59-74, 2012.

PADULA, Raphael. Integração regional de infra-estrutura e comércio na América do Sul nos anos 2000: uma análise políticoestratégica. (Tesis de Doutorado). COPPE/UFRJ, 2010. 311p.

PEDREIRA CAMPOS, Pedro. As origens da internacionalização das empresas de engenharia brasileiras. Empresas transnacionais brasileiras na América Latina: um debate necessário. Instituto Rosa Luxemburg Stifung. São Paulo Expressão Popular, p. 103-114, 2009.

RIGGIROZZI, Pía; TUSSIE, Diana. The Rise of Post-Hegemonic Regionalism in Latin America, The Rise of Post-Hegemonic Regionalism. The case of Latin America, en Pía Riggirozzi y Diana Tussie (Eds.), Vol. 4, p. 1-16. Dordrecht: Springer, 2012.

SANAHUJA, Antonio. Regionalismo post liberal y multilateralismo en Sudamérica: el caso de Unasur. El regionalismo “post-liberal” en América Latina y el Caribe: Nuevos actores, nuevos temas, nuevos desafíos. Anuario de la Integración Regional de América Latina y el Gran Caribe, A. Serbin, L. Martínez, \& H. R. Júnior, Bs. As., CRIES, 19-72, 2012.

SANAHUJA, Antonio. La crisis de la integración y el regionalismo en América Latina: giro liberal-conservador y contestación normativa. En MESA Manuela (coord..), Ascenso del nacionalismo y el autoritarismo en el sistema internacional. Anuario CEIPAZ 2018-2019, pp.107-127, Madrid, 2019.

SIMONOFF, Alejandro. Tenés el mate lleno de infelices ilusiones: la estrategia de inserción internacional del gobierno de Macri (2015 2019). Relaciones Internacionales n.57, p. 241- 269, 2019.

SOARES DE LIMA, Maria Regina. Relações interamericanas: a nova agenda sul-americana e o brasil. Lua Nova, São Paulo, 90, p. 167201, 2013.

SOUZA, Amaury. O Brasil na região e no mundo: percepções da comunidade brasileira de política externa. Rio de Janeiro: CEBRI, Centro Brasileiro de Relações Internacionais, 2008.

WEGNER, Rubia Cristina. Integração e desenvolvimento econômico: estratégias de financiamento do investimento de infraestrutura sul-americana. Economía y Sociedad, Campinas, v.27, n.64, 909-938, 2018.

ZIBECHI, Raúl. Brasil potencia: entre a integraçao regional e um novo imperialismo. Traducao Carlos Walter Porto- Goncalves. Río de Janeiro: Consequencia, 2012 


\section{Entrevistas citadas}

ENTREVISTADO 1: Funcionario del PCdoB. Asesor en Relaciones Internacionales del PCdoB. Entrevista realizada por la autora el 23/11/2017 en São Paulo, Brasil.

ENTREVISTADO 2: Asesor de la Presidencia en materia de Relaciones Internacionales, durante los gobiernos de Lula da Silva. Entrevista realizada por la autora el 16/11/2017 en São Bernardo Campo, Brasil.

ENTREVISTADO 3: Director de Asuntos Económicos de la UNASUR. Entrevista realizada por la autora el 22/09/2017 en São Paulo, Brasil.

ENTREVISTADO 4: Coordinadora Nacional Alterna ante el Consejo de Delegadas y Delegados de la Unión de Naciones Suramericanas (UNASUR), en representación de Argentina, hasta el año 2010. Entrevista realizada el 21/03/2016 en Buenos Aires, Argentina. 